TITLE:

\title{
A New Species of Horseshoe Bat of the Genus Rhinolophus from China (Chiroptera: Rhinolophidae)
}

$\operatorname{AUTHOR}(\mathrm{S}):$

Wu, Yi; Motokawa, Masaharu; Harada, Masashi

CITATION:

Wu, Yi ... [et al]. A New Species of Horseshoe Bat of the Genus Rhinolophus from China (Chiroptera: Rhinolophidae). Zoological Science 2008, 25(4): 438-443

\section{ISSUE DATE:}

2008-04

URL:

http://hdl.handle.net/2433/85312

RIGHT:

(c) 日本動物学会 / Zoological Society of Japan 


\title{
A New Species of Horseshoe Bat of the Genus Rhinolophus from China (Chiroptera: Rhinolophidae)
}

\author{
Yi Wu ${ }^{1}$, Masaharu Motokawa ${ }^{2 *}$ and Masashi Harada ${ }^{3}$ \\ ${ }^{1}$ College of Life Science, Guangzhou University, Guangzhou 510006, China \\ ${ }^{2}$ Kyoto University Museum, Kyoto 606-8501, Japan \\ ${ }^{3}$ Laboratory Animal Center, Graduate School of Medicine, \\ Osaka City University, Osaka 545-8585, Japan
}

\begin{abstract}
A new species of the Rhinolophus philippinensis group (Chiroptera: Rhinolophidae) is described from Guangdong, Guangxi, and Jiangxi Provinces in China. Rhinolophus huananus n. sp. is characterized by the horseshoe, as well as by external and cranial characteristics that separate it at the species level from the other members of the philippinensis group. One of the small species of the philippinensis group, $R$. huananus is intermediate in size between smaller $R$. siamensis and larger R. macrotis.
\end{abstract}

Key words: Chiroptera, Rhinolophidae, Rhinolophus, taxonomy, new species, China

\section{INTRODUCTION}

The genus Rhinolophus, horseshoe bats, is the only genus in the family Rhinolophidae and includes 71 species distributed in the Old World (Csorba et al., 2003). These 71 species are classified into 15 species groups on the basis of morphological characters. The Rhinolophus philippinensis species group includes six species from Southeast Asia and China (Csorba et al., 2003): R. macrotis Blyth, 1844; $R$. marshalli Thonglongya, 1973; R. paradoxolophus (Bourret, 1951); R. rex Allen, 1923; R. montanus Goodwin, 1979; and R. philippinensis Waterhouse, 1843. Rhinolophus macrotis is distributed in Southeast Asia, the Himalayan region, and southern China; $R$. montanus is a rare species distributed in Timor, Indonesia; $R$. philippinensis is distributed on islands from the Philippine Islands of Luzon to New Guinea and NE Queensland, Australia; and the other three species ( $R$. marshalli, R. paradoxolophus, and $R$. rex) are distributed continental Southeast Asia and China (Corbet and Hill, 1992; Csorba et al., 2003; Wang, 2003; Wu et al., 2004). These six species of the philippinensis group are very different from one another in noseleaf morphology, as illustrated by Csorba et al. (2003); thus they are easily identified by external characters.

Simmons (2005) listed an additional species, $R$. siamensis Gyldenstolpe, 1917, originally described from Doi Par Sakang, northwestern Thailand, as a member of the philippinensis group. This species was formerly considered to be a subspecies of $R$. macrotis (e.g., Csorba et al., 2003). According to Simmons (2005), $R$. siamensis is distributed in Thailand, Laos, and Vietnam and is distinct from $R$. macrotis in having much smaller body size. Simmons (2005) also suggested

\footnotetext{
* Corresponding author. Phone: +81-75-753-3287; Fax : +81-75-753-3276;

E-mail: motokawa@ inet.museum.kyoto-u.ac.jp
} doi: $10.2108 / z s j .25 .438$ that $R$. siamensis is sympatrically distributed with $R$. macrotis in several localities in Lao PDR and Vietnam, based on the literature (Francis et al., 1999; Hendrichsen et al., 2001; Csorba et al., 2003). Here we follow Simmons (2005) in recognizing $R$. siamensis as a valid species.

Among members of the philippinensis group, $R$. macrotis is more broadly distributed than other members, occurring in the Philippines, Sumatra, Malay Peninsula, Vietnam, Thailand, Lao PDR, Myanmar, China, Nepal, India, and Pakistan. It includes six subspecies (Bates and Harrison, 1997; Heaney et al., 1998; Francis et al., 1999; Csorba et al., 2003; Bates et al., 2004): the nominotypical subspecies, $R$. macrotis macrotis, in Nepal and India, originally described from Nepal (restricted to the Katmandu Valley by Scully [1887]) (also see Csorba and Bates, 1995); $R$. macrotis hirsutus Andersen, 1905, in the Philippines, originally described from Guimaras Island; $R$. macrotis dohrni Andersen, 1907, in Sumatra and Malaysia, originally described from Soekaranda, Deli, northwest Sumatra; $R$. macrotis episcopus Allen, 1923, in Sichuan Province and Chongqing City in China, originally described from Wanhsien, east of Sichuan Province (now Chongqing City); R. macrotis caldwelli Allen, 1923, in southeastern China (Fujian and Guangxi Provinces) and Vietnam, originally described from Yuki, Fujian Province, China; and R. macrotis topali Csorba and Bates, 1995, in Pakistan, originally described from Kakul Phosphate Mine, Abbotabad.

Throughout its distributional range, $R$. macrotis is considered to be common, but it is poorly represented in zoological collections (Csorba and Bates, 1995; Bates and Harrison, 1997; Heaney et al., 1998; Csorba et al., 2003). We collected 25 specimens of the philippinensis group from Guangdong, Jiangxi, Guangxi, and Sichuan Provinces and Chongqing (Wanhsien) City, China, in recent years. Among these specimens, we discovered $R$. macrotis and an undescribed species. In this paper, we describe the latter as a new species of the philippinensis group, and discuss 
several taxonomic problems among $R$. macrotis subspecies and $R$. siamensis.

\section{MATERIALS AND METHODS}

Six specimens of both sexes of the new species were studied; these specimens are preserved in fluid, with the skulls extracted. All individuals were captured in three caves from 2 October 1999 to 16 January 2001. After capture, bats were transferred into cloth bags and weighed to the nearest $0.1 \mathrm{~g}$, and a set of 10 external measurements was made on each specimen. The external measurements were taken to the nearest $0.1 \mathrm{~mm}$ with ordinary dial calipers. A set of 19 cranial measurements was taken in the laboratory to the nearest $0.01 \mathrm{~mm}$ with electronic calipers.

The following external measurements were taken: HB, head and body length; FA, length of forearm; TAIL, tail length; EAR, length of ear conch; SELLAH, height of sella from the cup at the base; SELLAW, width of sella at the middle; HSHOEW, greatest width of anterior noseleaf; MET3L, length of the metacarpal of the third finger; MET4L, length of the metacarpal of the fourth finger; MET5L, length of the metacarpal of the fifth finger.

The following cranial measurements were taken: SL, total length of skull, from front of canines to occiput; $\mathrm{UCM}^{3} \mathrm{~L}$, crown length of upper $\mathrm{C}-\mathrm{M}^{3}$; $\mathrm{UCP}^{4} \mathrm{~L}$, crown length of upper $\mathrm{C}-\mathrm{P}^{4}$; $U M^{1} M^{3} L$, crown length of upper $M^{1}-M^{3}$; $P L$, length of palatal bridge; $\mathrm{CCW}$, width of rostrum between outer margins of crown of canines; $\mathrm{M}^{3} \mathrm{M}^{3} \mathrm{~W}$, width of rostrum between outer margins of crown of $\mathrm{M}^{3}$; $\mathrm{KW}$, width of nasal knob; IOW, width of interorbital constriction; ZW, width of skull between zygomata; $\mathrm{MW}$, mastoid width of skull; $\mathrm{BCH}$, height of braincase, from glenoid fossa to top with sagittal crest; $\mathrm{KH}$, height of nasal knob, from palate to top; $\mathrm{ML}$, length of mandible, between hindermost portion of articular process and anteriormost edge of $\mathrm{I}_{1}$ alveolus; $\mathrm{LCM}_{3} \mathrm{~L}$, crown length of lower $\mathrm{C}-\mathrm{M}_{3}$; $L C \mathrm{P}_{4} \mathrm{~L}$, crown length of lower $C-P_{4} ; L M_{1} M_{3} L$, crown length of lower $M_{1}-M_{3}$; $\mathrm{CH}$, height of coronoid process, between its top and the sinus on ventral profile of mandibular body.

Comparative specimens examined were as follows. Rhinolophus macrotis episcopus: Sichuan Province, China, S2000-207, S2000-208, S8381, S8383, S98006; Wanhsien, Chongqing City, China, S05018, S05019. Rhinolophus macrotis caldwelli: Guangdong Province, China, G01057, G01058, G0483, G0484, G05061, G05062, G05064.

These specimens are deposited in the Institute of Biodiversity in Huanan, Guangzhou University, Guangzhou, China.

\section{SYSTEMATICS}

\section{Rhinolophus huananus sp. nov.}

(Figs. 1-6)

\section{Diagnosis}

A small species of the philippinensis group, size intermediate between smaller $R$. siamensis and larger $R$. macrotis. It differs from all other species by the combination of its short and not tongue-shaped sella, one small rounded pterygoid plate, and smaller external and cranial measurements. Rhinolophus huananus is further distinguished by having a deep, narrow interpterygoid between the hamular processes of the skull. The outline of the baculum is similar to that of $R$. pusillus; it has a very large and strong basal cone relative to the baculum of other horseshoe bats. The shaft is roughly cylindrical, with a slight thickening in the middle seen in lateral view.

\section{Etymology}

The new species is named after the institute to which the first author belongs, the Institute of Biodiversity in
Huanan (=China south), Guangzhou University.

\section{Holotype}

Adult female, G2001060 from Shuitou valley, $10 \mathrm{~km}$ from Yunling Zhen, Yingde City, Guangdong Province, China; collected on 16 January 2001; preserved in alcohol, with the skull extracted; deposited in the Institute of Biodiversity in Huanan, Guangzhou University, Guangzhou, China. Measurements (in millimeters) are given in Table 1.

\section{Paratypes}

Two adult males and three adult females collected by $\mathrm{Yi}$ Wu and others: G2000203, female, and G2000204, female, collected on 16 October 2000 at Bats Cave, Yangshan County, Guangdong Province, China; G99133, male collected on 2 October 1999, G2000119, male collected on 4 August 2000, and G2000143, female collected on 5 August 2000, all from Longyan Cave, Pinglin Zhen, Longmen County, Guangdong Province, China. All specimens were preserved in alcohol, with all skulls extracted, except for that of G2000143. These paratypes are deposited in the Institute of Biodiversity in Huanan, Guangzhou University, Guangzhou, China.

\section{Other specimens examined}

Rhinolophus huananus n. sp.: GX04180, GX04181, GX04182, all adult females, collected on 8 August 2004, at Longquanyan Cave, Xingye County, Guangxi Province, China; J3131, J3149, adult males collected on 1 July 1980, at Xianren Cave, Xiaoping valley, Ganxian county, Jiangxi Province, China. Specimens are deposited in the Institute of Biodiversity in Huanan, Guangzhou University, Guangzhou, China.

\section{Species description}

External characters. Small (forearm $39.30-43.12 \mathrm{~mm}$ ) rhinolophid bat. Noseleaves (Figs. 1 and 2) typical for group; anterior noseleaf covering the muzzle slightly, no distance between left and right leaves in the middle, secondary noseleaf present but under first, almost invisible. Connecting process rounded, originating below apex of sella, and higher than sella. Sella short (its length as long as width), not tongue shaped, covered with very short, pale hairs from base of sella downward.

Pelage (based on prepared skin of G2000143) from dorsal aspect: hairs in mid-dorsal region measure approximately $7.15 \mathrm{~mm}$; hairs on flanks and neck slightly longer. Hair bases pale, whitish, tips buffy brown to darker; those on nape of neck and shoulders darkest. Ventrally, hairs short, $5.87 \mathrm{~mm}$ in mid-ventral region; almost same length on flanks and outer aspects of throat. Hair bases grey-white; one-third of tips mid-buffy brown, nearly pale.

Membranes uniform, slightly dark brown; short, pale hairs present on outer border of interfemoral membrane.

Metacarpals subequal, third metacarpal shortest, fourth and fifth almost equal.

Cranial and dental characters (Figs. 3-5). Skull narrow, mastoid width exceeding zygomatic width. Sagittal crest not developed at all. Beside anterior median swellings of nasal knob, lateral knobs also well inflated. Palatal length almost as long as crown length of upper $\mathrm{M}^{1}-\mathrm{M}^{3}$. 
Table 1. External and cranial measurements (in $\mathrm{mm}$ ) of holotype and paratypes of Rhinolophus huananus new species.

\begin{tabular}{|c|c|c|c|c|c|c|}
\hline Character & $\begin{array}{c}\text { G2001060 } \\
\text { Female }\end{array}$ & $\begin{array}{c}\text { G2000203 } \\
\text { Female }\end{array}$ & $\begin{array}{c}\text { G99133 } \\
\text { Male }\end{array}$ & $\begin{array}{c}\text { G2000204 } \\
\text { Female }\end{array}$ & $\begin{array}{c}\text { G2000119 } \\
\text { Male }\end{array}$ & $\begin{array}{c}\text { G2000143 } \\
\text { Female }\end{array}$ \\
\hline $\mathrm{HB}$ & 33.49 & 34.63 & 40.00 & 38.47 & 36.45 & 38.20 \\
\hline $\mathrm{FA}$ & 40.95 & 41.70 & 39.30 & 41.97 & 39.46 & 41.00 \\
\hline TAIL & 16.10 & 20.16 & 14.00 & 17.54 & 21.48 & 22.00 \\
\hline EAR & 22.59 & 19.43 & 21.50 & 21.67 & 21.28 & 21.00 \\
\hline SELLAH & 3.43 & 3.17 & 3.56 & 3.26 & 3.44 & - \\
\hline SELLAW & 2.97 & 2.73 & 3.09 & 2.54 & 3.04 & - \\
\hline HSHOEW & 6.17 & 6.84 & 7.39 & 6.11 & 7.63 & - \\
\hline MET3L & 29.27 & 29.20 & 29.93 & 30.40 & 30.06 & - \\
\hline MET4L & 29.86 & 30.77 & 31.13 & 31.69 & 31.69 & - \\
\hline MET5L & 30.46 & 30.63 & 31.17 & 31.33 & 31.09 & - \\
\hline SL & 16.76 & 16.17 & - & 16.62 & 16.40 & 16.60 \\
\hline $\mathrm{UCM}^{3} \mathrm{~L}$ & 5.95 & 5.82 & 5.91 & 5.80 & 5.89 & 5.96 \\
\hline $\mathrm{UCP}^{4} \mathrm{~L}$ & 2.66 & 2.59 & 2.72 & 2.71 & 2.60 & 2.74 \\
\hline $\mathrm{UM}^{1} \mathrm{M}^{3} \mathrm{~L}$ & 3.34 & 3.27 & 3.34 & 3.35 & 3.22 & 3.38 \\
\hline PL & 3.24 & 3.06 & 2.95 & 3.28 & 3.21 & 3.22 \\
\hline UCCW & 3.43 & 3.36 & 3.11 & 3.51 & 3.46 & 3.55 \\
\hline $\mathrm{UM}^{3} \mathrm{M}^{3} \mathrm{~W}$ & 5.21 & 5.19 & 5.03 & 5.37 & 5.25 & 5.40 \\
\hline $\mathrm{KW}$ & 4.30 & 4.17 & - & 4.22 & 4.27 & 4.15 \\
\hline IOW & 2.26 & 2.33 & - & 2.38 & 2.41 & 2.47 \\
\hline ZW & 7.71 & 7.67 & - & 7.69 & 7.70 & 7.71 \\
\hline MW & 8.27 & 8.36 & - & 8.18 & 8.23 & 8.18 \\
\hline $\mathrm{BCH}$ & 5.38 & 5.19 & - & 5.48 & 5.50 & 5.57 \\
\hline $\mathrm{KH}$ & 3.14 & 3.08 & - & 2.89 & 3.06 & 3.11 \\
\hline$M L$ & 10.09 & 10.27 & - & 10.47 & 9.95 & 10.42 \\
\hline $\mathrm{LCM}_{3} \mathrm{~L}$ & 6.08 & 5.81 & - & 6.15 & 6.14 & 5.97 \\
\hline $\mathrm{LCP}_{4} \mathrm{~L}$ & 2.28 & 1.92 & - & 2.08 & 2.15 & 2.03 \\
\hline $\mathrm{LM}_{1} \mathrm{M}_{3} \mathrm{~L}$ & 3.76 & 3.71 & - & 3.69 & 3.65 & 3.59 \\
\hline $\mathrm{CH}$ & 2.18 & 2.02 & - & 2.08 & 2.04 & 2.07 \\
\hline
\end{tabular}

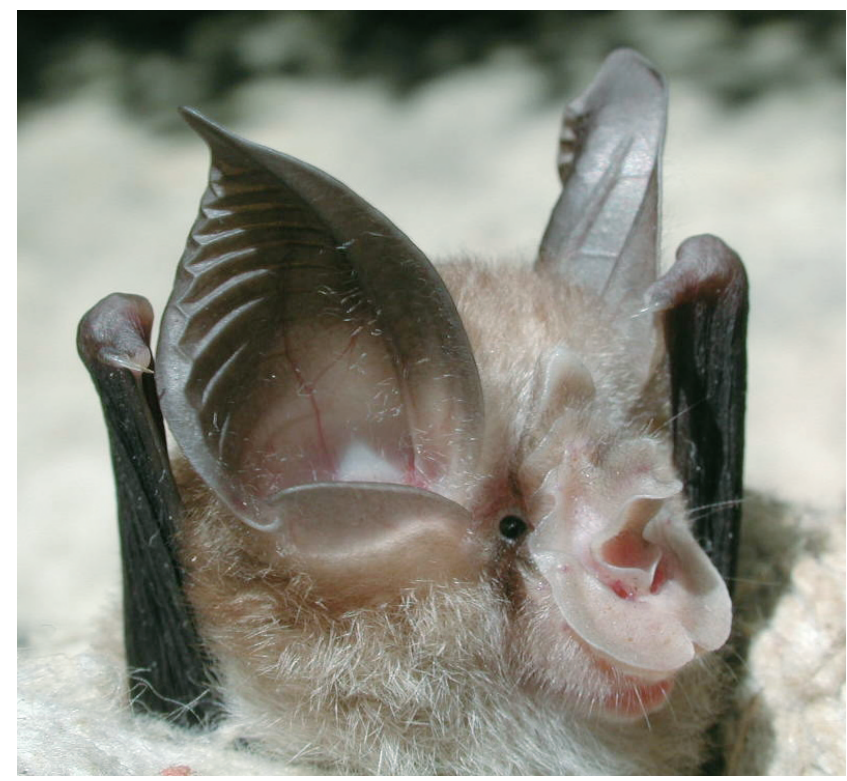

Fig. 1. Face of Rhinolophus huananus n. sp.
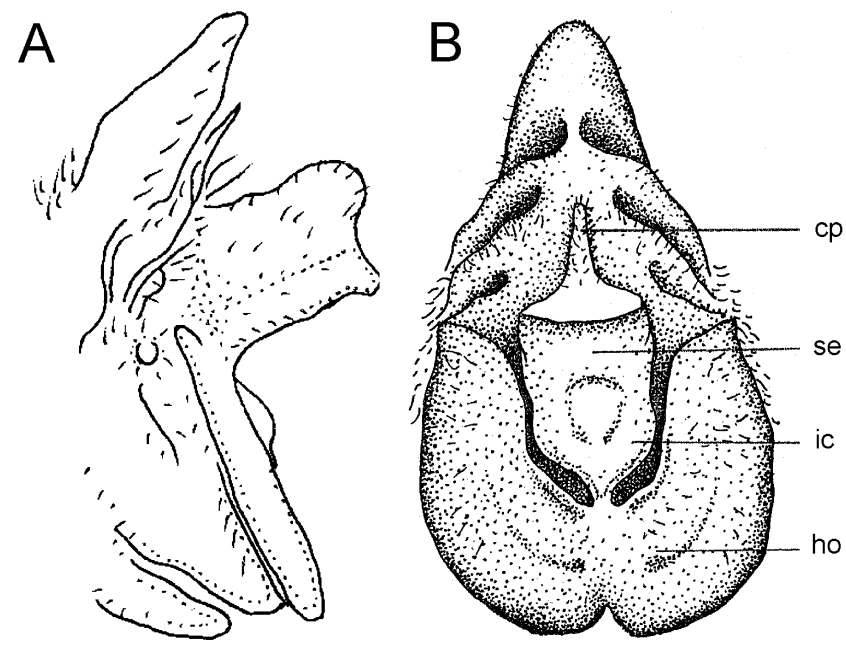

$2 \mathrm{~mm}$

Fig. 2. (A) Lateral and (B) frontal views of the horseshoe and sella of the holotype (G2001060) of Rhinolophus huananus n. sp. Abbreviations: $c p$, connecting process; se, sella; ic, internarial cup; ho, horseshoe. 


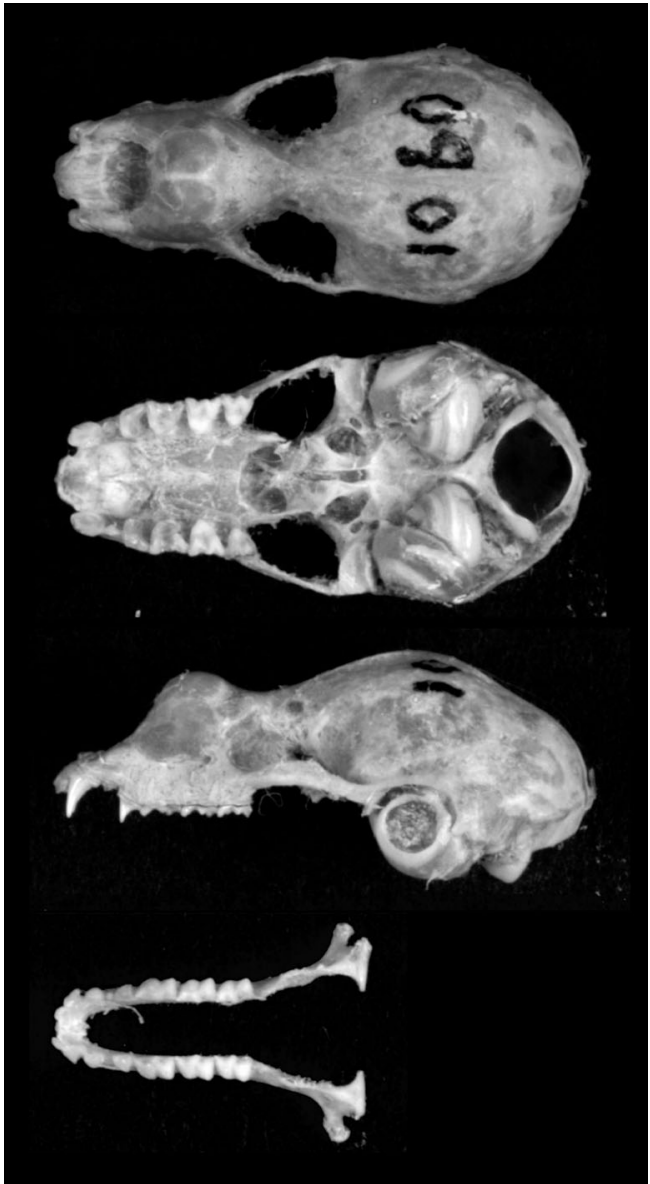

Fig. 3. Dorsal, ventral, and left lateral views of the skull and occlusal view of the mandible of the holotype (G2001060) of Rhinolophus huananus n. sp.

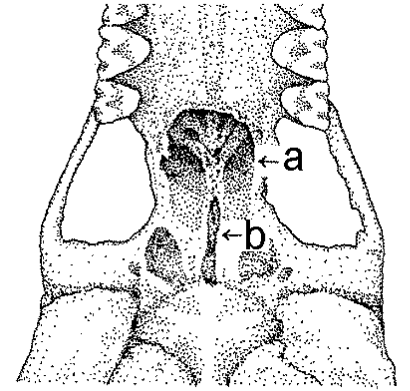

A

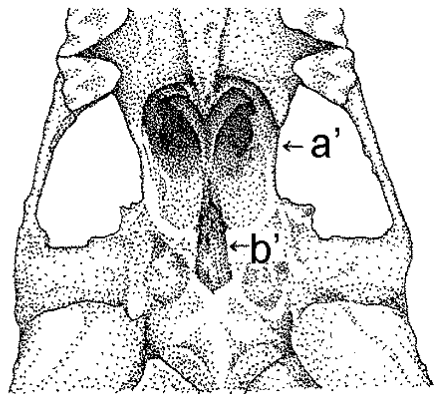

$2 \mathrm{~mm}$
Fig. 4. Ventral skull view of the holotype of (A) Rhinolophus huananus n. sp (G2001060) and (B) R. macrotis caldwelli (G05062); a, small rounded pterygoid plate; a', two divided horseshoe-shaped pterygoid plate; b, deep, narrow interpterygoid; b', cone-shaped interpterygoid.

First upper premolar $\left(\mathrm{P}^{2}\right)$ small but in tooth row, with a distinct cusp. Lower first premolar $\left(\mathrm{P}_{2}\right)$ also present in tooth row.

Baculum (Fig. 6A). Similar in general outline to that of $R$. pusillus; basal cone very large and strong compared to the other horseshoe bats; shaft roughly cylindrical, with a

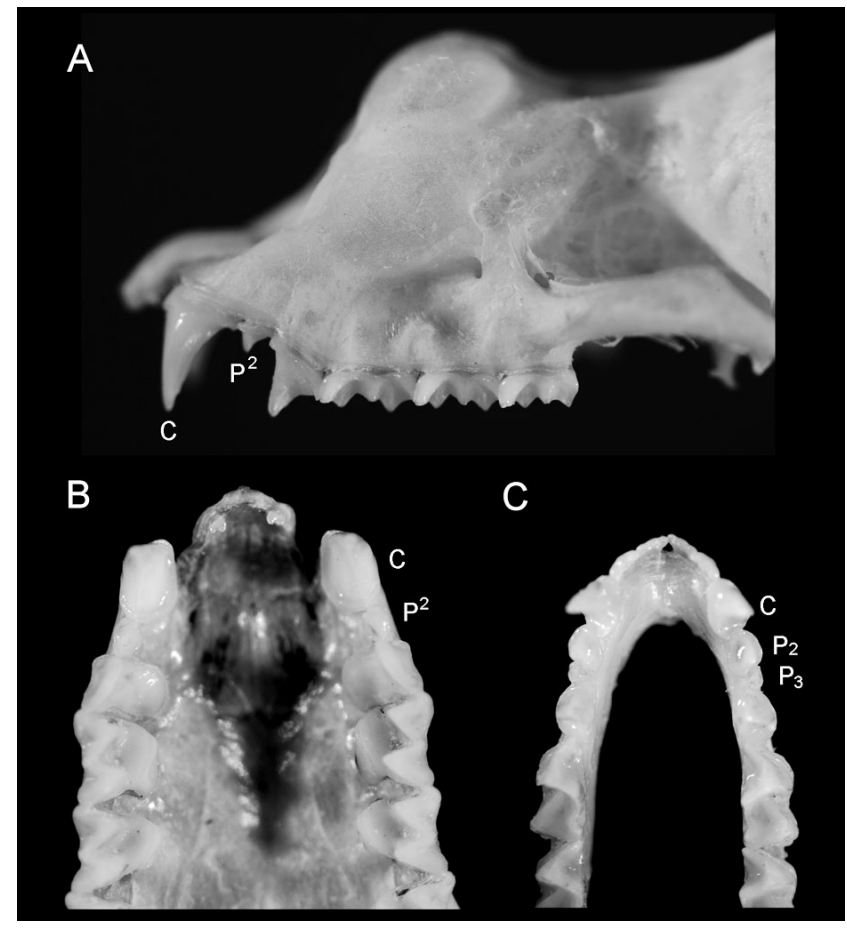

Fig. 5. (A) Left lateral and (B) crown views of the upper premolars, and (C) crown view of the lower premolars of Rhinolophus huananus n. sp (G2000203).

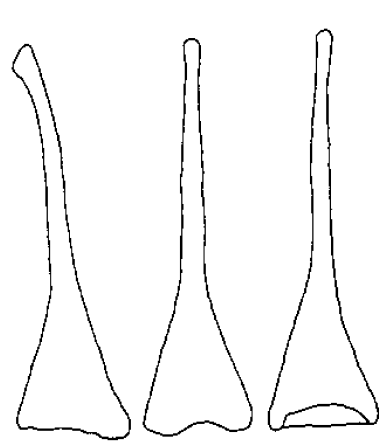

A

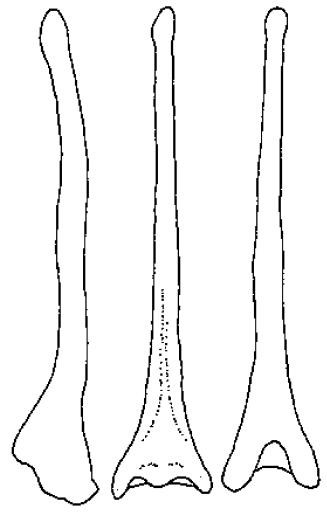

B
Fig. 6. Comparison of the baculum between (A) Rhinolophus huananus n. sp (G2000119) and (B) R. macrotis (modified from Csorba, 2003); lateral, dorsal, and ventral views from left to right.

slight thickening in the middle when viewed from dorsal aspect. Total length of the baculum, $3.82 \mathrm{~mm}$; greatest width, $1.02 \mathrm{~mm}$; length of shaft, $2.22 \mathrm{~mm}$ (width $0.2 \mathrm{~mm}$ ); length of basal cone, $1.30 \mathrm{~mm}$ (width $1.02 \mathrm{~mm}$ ). Tip of shaft narrowly rounded off, with lateral widening; shaft length, 0.5 $\mathrm{mm}$ (width $0.4 \mathrm{~mm}$ ). Basal cone $34.03 \%$ of baculum length; its width five times shaft width.

\section{Comparisons}

Rhinolophus huananus belongs to the philippinensis 
Table 2. Means, ranges, and sample sizes of the external and cranial measurements (in $\mathrm{mm}$ ) of $R$. huananus $\mathrm{n}$. sp., $R$. $m$. episcopus, and R. m. caldwelli from China, and R. siamensis. Data for R. siamensis were taken from literatures based on four specimens: holotype (Gyldenstolpe, 1917), paratype (Gyldenstolpe, 1917; Hendrichsen et al., 2001), one Thai specimen (Csorba and Bates, 1995), and one Vietnam specimen (Hendrichsen et al., 2001, reported as "R. macrotis").

\begin{tabular}{lcccc}
\hline Character & R. huananus & R. macrotis episcopus & R. macrotis caldwelli & R. siamensis \\
\hline FA & $41.35(39.30-43.12,11)$ & $47.32(45.80-48.96,7)$ & $49.28(45.94-51.23,7)$ & $36.60(36.1-37.1,2)$ \\
TAIL & $18.99(14.00-22.00,11)$ & $21.03(19.06-22.29,6)$ & $20.64(19.10-21.96,7)$ & $14.15(13.0-15.3,2)$ \\
HSHOEW & $6.76(5.52-7.63,9)$ & $8.07(7.57-8.44,6)$ & $8.21(7.63-9.09,7)$ & - \\
SELLAH & $3.47(3.17-3.81,9)$ & $5.19(4.13-5.93,6)$ & $5.91(4.98-6.65,7)$ & - \\
SELLAW & $2.73(2.33-3.09,9)$ & $3.39(3.05-3.78,6)$ & $3.86(3.56-4.21,7)$ & - \\
SL & $16.60(16.17-16.86,7)$ & $18.77(18.23-19.22,7)$ & $19.48(19.31-19.80,6)$ & $15.20(15.2-15.6,3)$ \\
UCM $^{3} \mathrm{~L}$ & $5.91(5.80-6.06,9)$ & $6.84(6.43-7.10,7)$ & $7.12(7.01-7.21,6)$ & $5.40(5.3-5.5,3)$ \\
$\mathrm{UM}^{1} \mathrm{M}^{3} \mathrm{~L}$ & $3.36(3.22-3.57,9)$ & $4.01(3.92-4.18,7)$ & $4.18(3.92-4.43,6)$ & $3.45(3.45,1)$ \\
$\mathrm{UCCW}$ & $3.42(3.11-3.55,9)$ & $3.96(3.59-4.13,7)$ & $4.17(3.95-4.29,6)$ & $3.54(3.4-3.82,3)$ \\
$\mathrm{UM}^{3} \mathrm{M}^{3} \mathrm{~W}$ & $5.28(5.03-5.40,9)$ & $6.01(5.81-6.17,7)$ & $6.30(6.09-6.47,6)$ & $5.16(5.0-5.29,3)$ \\
ZW & $7.72(7.67-7.85,7)$ & $8.47(7.99-8.94,7)$ & $8.94(8.77-9.11,6)$ & $7.00(6.9-7.1,3)$ \\
$\mathrm{LM}_{1} \mathrm{M}_{3} \mathrm{~L}$ & $3.70(3.59-3.84,8)$ & $4.34(4.17-4.46,7)$ & $4.53(4.42-4.67,6)$ & $3.87(3.87,1)$ \\
\hline
\end{tabular}

group among 15 species group of the genus Rhinolophus, according to key provided by Csorba et al. (2003). Rhinolophus huananus agree with the following keys defined for the philippinensis group: specimens outside the Palaearctic Region (key number 10); specimens from the Indomalayan, Oceanian, and Australian Regions (24); sella lacking lateral basal lappets (26); connecting process rounded, not pointed (32); connecting process usually better developed, its tip pointed more or less forward; zygomata more robust, medio-laterally flattened (34); connecting process not forming a continuous arch (38); and sella long and wide; palatal bridge more than $1 / 3$ length of maxillary tooth row $\left(\mathrm{CM}^{3}\right)$ (39).

Rhinolophus huananus differs from all other species of the philippinensis group. It is a small species for this group. External and cranial measurements are intermediate between those of smaller $R$. siamensis and the remaining larger species, especially the length of the forearm: $R$. huananus, $39.30-43.12 \mathrm{~mm}$ (this study); $R$. siamensis, 36.1-37.1 mm (Table 2); $R$. macrotis, $39-48 \mathrm{~mm} ; R$. marshalli, 46-48 mm; $R$. paradoxolophus, $50.5-57 \mathrm{~mm} ; R$. rex, $56.5-63 \mathrm{~mm}$; $R$. montanus, $43.5-46 \mathrm{~mm}$; and $R$. philippinensis, 47-57 mm (Csorba et al., 2003). Forearm length overlaps with that of $R$. macrotis. The values of $R$. macrotis were taken from Csorba et al. (2003), and they may include $R$. siamensis as a subspecies; therefore, the value for $R$. huananus likely overlaps only with that of $R$. siamensis. The mean value of forearm length of each subspecies of $R$. macrotis is almost equal to or larger than the maximum value of $R$. huananus, as follows: $R$. m. macrotis, $42.79 \mathrm{~mm}$; R. m. dohrni, $43.82 \mathrm{~mm}$; R. m. topali, $45.36 \mathrm{~mm}$ (Csorba and Bates, 1995); R. m. hirsutus, $43.50 \mathrm{~mm}$ (Ingle and Heaney, 1992); R. m. caldwelli, $49.28 \mathrm{~mm}$; and R. m. episcopus, $47.32 \mathrm{~mm}$ (this study). The mean value of tail length of $R$. huananus ( $17.86 \mathrm{~mm}$, Table 2$)$ is greater than that of $R$. m. siamensis $(13.0,15.3 \mathrm{~mm})$.

The sella of $R$. huananus differs from that of $R$. rex, $R$. paradoxolophus, $R$. marshalli, $R$. philippinensis, and $R$. montanus in not having an expanded internarial region, a character also shared with $R$. macrotis and $R$. siamensis. The sella of $R$. huananus differs from those of all subspecies of $R$. macrotis by its shorter size $(3.47 \times 2.73 \mathrm{~mm})$, and in not being tongue shaped (Fig. 2). The sella is larger and tongue shaped in all subspecies of $R$. macrotis (e.g., Csorba et al., 2003).

Rhinolophus huananus is further distinguished from $R$. macrotis in skull characteristics, as follows: (1) in having one small, rounded pterygoid plate in the ventral view of the skull, instead of two divided horseshoe-shaped pterygoid plate of the skull of $R$. macrotis; and (2) in having a deep, narrow interpterygoid between hamular processes in ventral view, instead of the cone-shaped interpterygoid of the skull of $R$. macrotis (Fig. 4). The outline of the baculum of $R$. huananus is similar to that of $R$. pusillus (see Csorba et al., 2003), but is different from that of $R$. macrotis. It has a very large, strong basal cone relative to the bacula of the other horseshoe bats (e.g., Csorba et al., 2003). The shaft is roughly cylindrical, with a slight thickening in the middle in dorsal view, while the shaft of baculum of $R$. macrotis is longer and the basal cone not so thick in dorsal view (Fig. 6).

\section{DISCUSSION}

Rhinolophus huananus described in this paper is a new species of the philippinensis group of the genus Rhinolophus, and is more similar to $R$. macrotis and $R$. siamensis than to the other species. Rhinolophus huananus is smaller than all subspecies of $R$. macrotis, and is intermediate in size between $R$. siamensis and $R$. macrotis. The FA measurement reported for the holotype of $R$. m. caldwelli from Yuki, Fujian, is $43 \mathrm{~mm}$ (Allen, 1923), within the variation of $R$. huananus (Table 2, 39.30-43.12 mm), but the skull size corresponding to $\mathrm{SL}$ is $18 \mathrm{~mm}$ in that specimen, much larger than in $R$. huananus $(16.17-16.86 \mathrm{~mm})$.

The specific status of $R$. siamensis was confused and has been discussed by several authors. We also discuss its specific status in relation with the validity of $R$. huananus. Rhinolophus siamensis was originally described by Gyldenstolpe (1917) on the basis of two specimens collected from Doi Par Sakeng, northwestern Thailand, as a subspecies of $R$. macrotis: $R$. $m$. siamensis. The specimens of siamensis are small, with a forearm length of $36.1 \mathrm{~mm}$ and total length of skull to front of canine of 15.4 and 15.3 $\mathrm{mm}$. From Vietnam, Osgood (1932) recorded both of the larger species $R$. episcopus caldwelli $(=R$. macrotis caldwelli) and $R$. macrotis siamensis. Osgood's (1932) 
siamensis was based on two specimens collected from Muong Moun; the forearm lengths of those specimens were 38 and $39 \mathrm{~mm}$. Osgood (1932) noted that "Comparison with published measurements indicates they are almost exactly intermediate between macrotis and siamensis". Francis et al. (1999) and Hendrichsen et al. (2001) recorded both $R$. macrotis and a smaller species resembling $R$. macrotis from Lao PDR and Vietnam, respectively. Francis et al. (1999) referred to the smaller species as "Rhinolophus cf. siamensis". Hendrichsen et al. (2001), on the other hand, identified both a $R$. macrotis specimen and a smaller specimen as $R$. macrotis. Forearm lengths of the two specimens were 45.0 and $37.1 \mathrm{~mm}$, very different from one another (Hendrichsen et al., 2001). Hendrichsen et al. (2001) also examined a paratype of siamensis, and he pointed out that siamensis and macrotis are different in overall size, but show essentially identical dentition and cranial characters, except for the basisphenoid pit and first upper premolar $\left(\mathrm{P}^{2}\right)$. The basisphenoid pits were long and narrow in siamensis, but much wider and oval in macrotis; $\mathrm{P}^{2}$ was minute in siamensis, while considerable larger and more robust in macrotis. Although Hendrichsen et al. (2001) might have validated the taxonomic status of siamensis; these authors included siamensis within $R$. macrotis. Simmons (2005) first considered $R$. siamensis to be a valid species based on Francis et al. (1999) and Hendrichsen et al. (2001), without providing additional data. In this study, $R$. huananus showed a wider, more oval basisphenoid pit and a large, robust $P^{2}$ (Figs. 4 and 5). These characters are similar to those of $R$. macrotis, but different from those of $R$. siamensis, and they are likely useful in distinguishing $R$. huananus from $R$. siamensis.

Rhinolophus huananus likely inhabits forests and has been recorded from Guangdong, Guangxi, and Jiangxi Provinces (this study). These areas correspond to part of the Indochinese and southern Chinese divisions of the Indomalayan region, following the mammalian zoogeographical subdivisions of Corbet and Hill (1992). In China, both $R$. huananus and $R$. m. caldwelli were collected in a narrow range from Yingde City, Guangdong Province (in caves about $10 \mathrm{~km}$ apart). These collection data strongly suggest the sympatry of $R$. huananus and $R$. $m$. caldwelli in southern China, although we did not get samples of both species from a single cave. Possible sympatry between $R$. huananus and $R$. macrotis may offer additional evidence to support the valid specific status of both species. In that area, $R$. huananus is clearly distinct from $R$. macrotis in external and cranial characters as well as baculum morphology. Differences in baculum morphology may strongly suggest the occurrence of reproductive isolation between $R$. huananus and $R$. macrotis. Future studies to clarify the detailed distribution of $R$. huananus and $R$. macrotis in China and adjacent countries are necessary to explore the evolutionary history of the philippinensis group bats in the southern part of China.

\section{ACKNOWLEDGMENTS}

We thank the National Natural Science Foundation of China (NSFC, No. 30370167, 30670277), the National Study Abroad Foundation of China (No. 21844046), the Kyoto University Foundation, the Japan Society for the Promotion of Science (JSPS, L06554), and NSFC-JSPS Joint Research Project grant (No. 20085). We also thank James W. Orr for critical comments on an earlier version of the manuscript.

\section{REFERENCES}

Allen GM (1923) New Chinese bats. Am Mus Novit 85: 1-8

Andersen K (1905) On the bats of the Rhinolophus macrotis group, with descriptions of two new forms. Ann Mag Nat Hist Ser 7 16: 289-292

Andersen K (1907) Chiropteran notes. Ann Mus Civ Stor Nat Giacomo Doria 3: 5-45

Bates PJJ, Harrison DL (1997) Bats of the Indian Subcontinent. Harrison Museum Publications, Sevenoaks

Bates PJJ, Mar Mar Thi, Tin Nwe, Si Si Hla Bu, Khin Mie Mie, Nyo Nyo, Aye Aye Khaing, Nu Nu Aye, Thida Oo, Mackie I (2004) A review of Rhinolophus (Chiroptera: Rhinolophidae) from Myanmar, including three species new to the country. Acta Chiropterol 6: 23-48

Blyth E (1844) Notices of various mammalia. J Asiatic Soc Bengal 13: $463-494$

Bourret R (1951) Une nouvelle chauve-souris du Tonkin, Rhinomegalophus paradoxolophus. Bull Mus Natl Hist Nat Paris 33: 607-609

Corbet GB, Hill JE (1992) The Mammals of the Indomalayan Region: A Systematic Review. Oxford University Press, Oxford

Csorba G, Bates PJJ (1995) A new subspecies of the horseshoe bat Rhinolophus macrotis from Pakistan (Chiroptera: Rhinolophidae). Acta Zool Acad Sci Hungaricae 41: 285-293

Csorba G, Ujhelyi P, Thomas N (2003) Horseshoe Bats of the World (Chiroptera: Rhinolophidae). Alana Books, Shropshire

Francis CM, Guillén A, Robinson MF (1999) Order Chiroptera: bats. In "Wildlife in Lao PDR: 1999 Status Report" Ed by JW Duckworth, RE Salter, K Khounboline, IUCN, Vientiane, pp 225-235

Goodwin RE (1979) The bats of Timor: systematics and ecology. Bull Am Mus Nat Hist 163: 73-122

Gyldenstolpe N (1917) Zoological results of the Swedish zoological expeditions to Siam 1911-1912 \& 1914-1915. V. Mammals II. K Svenska Vetensk-Akad Handl 57: 1-59

Heaney LR, et al. (1998) A synopsis of the mammalian fauna of the Philippine Islands. Field Zool New Ser 88: 1-61

Hendrichsen DK, Bates PJJ, Hayes BD, Walston JL (2001) Recent records of bats (Mammalia: Chiroptera) from Vietnam with six species new to the country. Myotis 39: 35-122

Ingle NR, Heaney LR (1992) A key to the bats of the Philippine Islands. Field Zool New Ser 69: 1-44

Osgood WH (1932) Mammals of the Kelly-Roosevelts and Delacour Asiatic Expeditions. Field Mus Nat Hist Zool Ser 18: 193-339

Scully J (1887) On the Chiroptera of Nepal. Asiatic Soc Bengal 56: 233-259

Simmons NB (2005) Order Chiroptera. In "Mammal Species of the World. A Taxonomic and Geographic Reference" 3rd ed Ed by DE Wilson, DM Reeder, The Johns Hopkins University Press, Baltimore, pp 312-529

Thonglongya K (1973) First record of Rhinolophus paradoxolophus (Bourret, 1951) from Thailand, with the description of a new species of the Rhinolophus philippinensis group (Chiroptera, Rhinolophidae). Mammalia 37: 587-597

Wang Y (2003) A Complete Checklist of Mammal Species and Subspecies in China. China Forestry Publishing, Beijing

Waterhouse GR (1843) On various species of bats collected by $\mathrm{H}$ Cuming, Esq in the Philippine Is. Proc Zool Soc Lond 1843: 6669

Wu Y, Yang QS, Xia L, Peng HY, Zhou ZM (2004) New record of Chinese bats: Rhinolophus marshalli. Chinese J Zool 39: 109110 [in Chinese with English abstract]

(Received April 9, 2007 / Accepted January 17, 2008) 